\title{
Religiosidad e identidad en San Francisco de Campeche. Siglos XVI y XVII*
}

\author{
Adriana Delfina Rocher Salas \\ Universidad Autónoma de Campeche
}

\begin{abstract}
Este trabajo estudia los problemas que acompañaron la gestación de una identidad propia y común para los residentes hispanos de la villa y puerto de San Francisco de Campeche durante el período colonial y la participación de elementos religiosos, particularmente el culto a los santos patronos, en el proceso. Teniendo como telón de fondo la peculiaridad de la región yucateca, donde una conflictiva relación entre españoles e indígenas impidió la utilización de elementos culturales prehispánicos en la formación de una conciencia identitaria, se analizan diversos factores, como las características de los santos tutelares de los barrios y de algunas corporaciones locales, los procesos de adopción, adaptación u olvido de sus cultos por parte del vecindario porteño y la participación de los diferentes sectores locales en la promoción de sus santos patronos.
\end{abstract}

PALABRAS ClAVE: Identidad, religiosidad, culto, santos patronos.

This study examines the problems concomitant to the development of a common identity among the Spanish settlers of San Francisco de Campeche during the Colonial period, with focus on the role played by religious elements in the shaping of this identity - in particular, the cult to the saints. An analysis of factors such as the characteristics of the saints in the neighborhood and local associations; processes of cult adoption, adaptation or dismissal; as well as the participation of the different local sectors in promoting the to their respective saints will be presented. This analysis will take into consideration the conflictive relationship between Spanish settlers and native people in Yucatán, a situation that prevented the using of aboriginal cultural elements in the shaping of a new identity.

KEYWORDS: Identity, religiosity, cult, saints.

La conquista y colonización de América significó el advenimiento de un mundo nuevo, no sólo para los pueblos conquistados, sino incluso para sus propios conquistadores. Confrontados con una realidad enteramente distinta a la vivida en sus lugares de origen, los españoles debieron adaptar sus esquemas institucionales, sociales y culturales a las circunstancias,

* Agradezco a las profesoras Cristina García Bernal y Elisa Luque Alcalde por su lectura y valiosos comentarios que, sin duda, contribuyeron a enriquecer este trabajo. 
ambientes y pueblos americanos. Y, al ser parte de un pueblo que tenía en la religión uno de sus principales referentes, la necesidad de encontrar la forma de adecuar sus prácticas religiosas a las demandas y ritmos impuestos por el proceso colonizador ocuparía un lugar prioritario en la agenda de aquellos que, temporal o definitivamente, harían de la América hispana su nuevo hogar.

La manera en que los conquistadores y colonizadores hispanos tuvieron que modificar su práctica religiosa, una vez asentados en el Nuevo Mundo, ha recibido relativamente poca atención por parte de los investigadores del fenómeno religioso durante el período colonial, más atraídos por el sincretismo religioso desarrollado por las culturas indígenas y también, aunque en menor medida, por las africanas. Tal disparidad produce una visión parcial de los procesos de adaptación y transformación de los referentes religiosos en los diferentes actores del período colonial, como si aquellos se hubiesen dado únicamente del lado de los pueblos conquistados, mientras que los españoles habrían alcanzado el éxito en su proyecto de crear una "Nueva España" en América.

Frente a tal premisa, debe oponerse otra, que considere cómo la religiosidad y las instituciones que surgen a partir de ella no sólo son el reflejo de una mentalidad y realidad social, sino también productos de las mismas. Dicho de otra forma, el sentimiento religioso y las instituciones que le dan cauce se explican a partir del medio cultural, social, geográfico y económico en que surgen. En el caso de los conquistadores hispanos y sus descendientes en el Nuevo Mundo, el proceso de adaptación de sus referentes religiosos acompañó a otro: el de la formación de su identidad. Efectivamente, no eran iguales a los españoles de la península, pero tampoco podían asimilarse a los nativos americanos; entonces, ¿qué eran?, ¿quiénes eran?, ¿en qué mundo se integraban?

Trabajos como los de Solange Alberro han puesto de manifiesto la presencia de elementos religiosos en el surgimiento de una identidad criolla. ${ }^{1}$ Nuestro trabajo pretende continuar la senda abierta por esas investigaciones, aunque con un objetivo más modesto: estudiar el proceso de gestación de un imaginario común para los españoles y sus descendientes asentados en la villa y puerto de San Francisco de Campe-

1 Alberro, Solange: Del gachupín al criollo. O de cómo los españoles dejaron de serlo. El Colegio de México, México, 2002; y El águila y la cruz. Orígenes religiosos de la conciencia criolla: México siglos XVI-XVII, Fondo de Cultura de México-Fideicomiso Historia de las Américas-El Colegio de México, México, 1999. 
che $^{2}$ y la participación de elementos religiosos — prehispánicos y/o hispanos - en el mismo, teniendo como eje de nuestro discurso la forma en que se desarrolló el culto a sus santos patronos, desde aquellos traídos por los conquistadores y primeros colonizadores, hasta los que se fueron imponiendo conforme a las circunstancias y problemas propios de la región. La causa de escoger el culto a los santos patronos como eje de nuestro trabajo tiene como principal motivación el papel del culto a los santos como factor en la formación de una conciencia identitaria. Así mismo, considerando la premisa de que la capacidad de expansión de cada uno de estos celestiales protectores estuvo vinculada tanto a su empatía con los anhelos y demandas locales, como a la presencia de una fuerza capaz de asegurar la continuidad del culto, se analizará el papel desempeñado por las diferentes corporaciones y sectores locales en la promoción de sus santos patronos.

\section{Antes de América: culto a los santos, sociedad e identidad}

Los españoles que fundaron San Francisco de Campeche trajeron consigo, además de sus armas y sueños de grandeza, la herencia de una sociedad de antiguo régimen, donde se concebía al sujeto más que como individuo, como parte integrante de una colectividad la cual, a la vez que proporcionaba seguridad, le permitía distinguirse del otro, del extranjero, tan desconocido como temido. Y uno de los elementos definidores del "ser" y el "no ser" era la religión. ${ }^{3}$

La religiosidad cohesionaba a la población en torno al culto a un santo patrono, su imagen o reliquias, al que se presentaba como protector de todos los miembros de la comunidad, sin importar origen social, racial o profesional. La relación del santo con su entorno comunitario se afianzaba o decaía dependiendo de su especialidad "profesional" y de su capacidad de proteger a sus fieles de todo mal, ya fueran guerras, epidemias, malas cosechas o desastres naturales. En una sociedad convencida de la inter-

2 Para efectos de este trabajo, llamaremos hispanos no sólo a los españoles y sus descendientes, sino también a aquellos sectores sociales que, si bien pertenecían a otros grupos raciales, culturalmente mostraban marcados rasgos hispanos.

3 Martínez Gil, Fernando: "Religión e identidad urbana en el arzobispado de Toledo (siglos XVI-XVII)", en Vizuete Mendoza, J. Carlos y Palma Martínez-Burgos García: Religiosidad popular y modelos de identidad en España y América, Ediciones de la Universidad de Castilla-La Mancha, Cuenca, 2000, págs. 15-57. 
acción entre los mundos espiritual y terrenal, la presencia de un poderoso santo patrono, capaz tanto de aplacar la furia divina como de tocar los corazones humanos era, pues, una necesidad tan natural como impostergable. ${ }^{4}$

El santo patrono, como patrimonio comunitario, además de fortalecer el sentimiento de pertenencia, afianzaba el de alteridad. Su presencia y sus virtudes ponían de manifiesto la preferencia divina por un grupo, población o pueblo determinados, en contraste con los "otros" que carecían de tan formidable aliado. De esta manera, se presentaba una relación de dependencia recíproca: un santo patrono podía proveer cohesión y legitimidad frente a otros, pero a la vez requería de una constante promoción y culto para asegurar su permanencia en la conciencia colectiva.

En la veneración a un santo patrono participaban lo mismo laicos que eclesiásticos, si bien eran éstos últimos los considerados como los intermediarios naturales entre Dios y el mundo. Este papel de mediación dotaba al estamento eclesiástico de legitimidad frente a los demás sectores sociales, convirtiéndolo en un grupo privilegiado, dueño de un capital social garantizado por su monopolio de la relación con lo divino. Así pues, si bien los seglares podían agruparse en cofradías, congregaciones o terceras órdenes, y de este modo acudir a las necesidades del culto a un santo patrono, debían contar siempre con la aprobación, presencia y apoyo del elemento eclesiástico. $^{5}$

La Iglesia estaba constituida por múltiples corporaciones que, pese a su común objetivo último, la salvación, se encontraban en una constante disputa por atraerse el mayor número de fieles posibles, disputa en la cual la promoción de sus propios santos, preferentemente aquellos salidos de sus filas, ocupaba un lugar primordial.

Este modelo de religiosidad confluía con una idea organicista de la sociedad, donde cada miembro trabajaba para conseguir la supervivencia del organismo. Esta idea servirá para justificar las desigualdades sociales, pues no todos los miembros de un cuerpo cumplen las mismas funciones ni tienen la misma importancia y, mucho menos, ocupan un mismo lugar. ${ }^{6} \mathrm{La}$ Iglesia tendrá un santo patrono o una advocación mariana para cada uno de esos miembros, poniendo a disposición de los distintos sectores sociales un

4 Brown, Peter: The cult of the saints, its rise and function in Latin Christianity, University of Chicago Press, Chicago, 1981.

5 Morgado García, Arturo: Ser clérigo en la España del Antiguo Régimen, Universidad de Cádiz, Cádiz, 2000, capítulos 6 y 7.

6 Ibídem, págs. 126-129. 
amplio santoral donde encontrar aliados divinos afines a casi cualquier profesión, raza o nivel social.

El trazado urbano respondía a la necesidad de establecer un orden, que se buscó quedara manifiesto en la estructura urbana, y España, que trasladó a sus colonias en América estos preceptos y modelos, impuso una traza en la cual, por lo menos formalmente, sus habitantes podían "vivir juntos, pero no revueltos". De este modo, cada poblado urbano se veía dividido en barrios, cada uno con su propia plaza, iglesia y santo patrono, en los cuales se agrupaba a la población de acuerdo a su perfil socio-profesional. Pero como en todo cuerpo, había un centro principal, un corazón que daba vida y sentido a todo el organismo, dotado de símbolos y representaciones que pretendían ser comunes a todos, y en el cual sobresalía la presencia de un santo patrono.

\section{San Francisco de Campeche: los primeros santos patronos}

La fundación de San Francisco de Campeche trajo añadida la construcción de estructuras institucionales y esquemas de convivencia social que, lógicamente, aspiraban a reproducir los de la metrópoli. Se repartieron solares, se erigió al cabildo y se bautizó a la villa con el nombre de San Francisco de Campeche, en honor a quien fue escogido como su santo patrono: San Francisco de Asís. Las causas que motivaron tal elección han hecho correr ríos de tinta a los historiadores campechanos. De este modo, unos opinan que la fundación se dio el día de la fiesta del serafín de Asís el 4 de octubre-; otros piensan que se quiso hacer un homenaje a los principales artífices de la conquista del territorio - los tres Francisco de Montejo, padre, hijo y sobrino-; incluso no ha faltado el despistado que lo ha adjudicado a la influencia de la orden de San Francisco, olvidando que los seráficos frailes estuvieron ausentes durante esos primeros años de colonización. ${ }^{7}$

La llegada de la orden de San Francisco afianzó el patronazgo del pobre de Asís. En el barrio de indígenas mayas, conocido como Campechuelo, los frailes fundaron un convento al que pusieron bajo el cuidado espiritual de su fundador, quien también daría su nombre al barrio. De esta manera, San Francisco tuvo bajo su protección a la villa, a un barrio y a un

7 Aunque su primera entrada en tierras yucatecas data de 1537 , no sería hasta 1545 cuando los franciscanos comenzaran de manera sistemática la tarea de evangelizar Yucatán y organizar la construcción de su edificio institucional. Al respecto, véase González Cicero, Stella María: Perspectiva religiosa en Yucatán. 1517-1571, El Colegio de México, México, 1978, capítulo V. 
convento con su iglesia, los que, a su vez, garantizaron la permanencia del culto y la veneración a su patriarca.

Pero antes que la iglesia franciscana se había erigido la iglesia parroquial que estaba dedicada a la virgen María en su advocación de la Inmaculada Concepción. La elección no resulta extraña, si consideramos la gran devoción de la Corona española por la Inmaculada y su activismo en la promoción de su culto. A lo largo y ancho del virreinato novohispano se habían fundado iglesias y conventos dedicados a la también conocida como la Purísima Concepción, por lo que la villa y puerto de San Francisco de Campeche sólo representó un pequeño punto más en el abigarrado mapa de la devoción inmaculista en el nuevo mundo.

Al parecer, la devoción al Santo Nombre de Jesús también tuvo presencia durante los primeros años de San Francisco de Campeche, como lo avala la presencia de una iglesia y un hospital con su patronazgo en el corazón mismo de la villa. La iglesia se constituyó en ayuda de parroquia, siendo utilizada para administrar los sacramentos a la población africana. ${ }^{8}$ Por su parte, el hospital tuvo una corta existencia, puesto que fue derribado a principios del siglo XVII para dar paso a la construcción de una nueva iglesia parroquial. ${ }^{9}$

A iniciativa de un particular, Pedro Martín de Bonilla, en la parte extramuros de la villa se construyó una ermita dedicada a Nuestra Señora de Guadalupe. La raíz extremeña del culto guadalupano parecía causa suficiente para convertirla en una de las devociones más celebradas de la localidad, habida cuenta del origen, extremeño también, de un alto porcentaje de los conquistadores y primeros pobladores de Campeche; sin embargo, esta empatía resultó insuficiente para atraer a más patronos que su fundador, quedando la iglesia carente de dote y a expensas de la generosidad y las posibilidades de los sucesores de Pedro Martín. ${ }^{10}$

8 Cárdenas y Valencia, Francisco de: Relación Historial eclesiástica de la provincia de Yucatán de la Nueva España, escrita en el año de 1639, Antigua Librería Robredo de José Porrúa e Hijos, 1937, pág. 90. Tal situación prevaleció durante todo el período colonial, pese a que el grueso de la población africana se concentraba en el barrio de Santa Ana. Echánove, Policarpio Antonio de: "Cuadro estadístico de Yucatán en 1814", en Pérez Betancourt, Antonio y Rodolfo Ruz Menéndez, (comp): Yucatán: textos de su historia, Secretaría de Educación Pública - Instituto Mora - Gobierno del Estado de Yucatán, México, 1988, pág. 46.

9 Archivo General de Indias (en adelante AGI), Escribanía 305A, El Cabildo Justicia y Regimiento de la Villa de Campeche a Gonzalo de Salazar, obispo de Yucatán, sobre las obras de la Iglesia Mayor de dicha villa, Mérida de Yucatán, 1610.

10 Fray Gregorio de Montalvo, obispo de Yucatán: "Memorial a la Corona sobre el estado de la Iglesia en Yucatán”, en Documentos para la Historia de Yucatán. II. La Iglesia en Yucatán. 15601610, Mérida, 1938. 
El otro barrio, destinado a albergar a los indios mexicas que acompañaron a Montejo, el mozo en la conquista de Campeche, recibió a San Román mártir como su santo tutelar. La historia de su elección gira en torno a una plaga de langosta, ocurrida "recién poblada la villa", cuando los vecinos, "buscando el divino auxilio ...echaron suertes para celebrar fiesta al santo cuyo nombre saliese", esperando que fuese una voluntad sobrenatural y no el deseo humano quien tomase la decisión. Desde entonces San Román fue homenajeado anualmente el día de su fiesta —el 9 de agostocon una procesión que salía de la iglesia parroquial con rumbo a su ermita extramuros, donde se cantaba "misa con sermón y alabanzas"."

Estos primeros protectores celestiales encontraron numerosos obstáculos que dificultaron el proceso de afianzar y, sobre todo, de expandir sus respectivos cultos. La escasa población, su carencia de recursos, el sentimiento de inseguridad provocado por el aún fresco recuerdo de la conquista, al que se añadió una incipiente actividad pirática que, para finales del siglo XVI se había transformado en una amarga realidad, fueron circunstancias que en su conjunto explican la imposibilidad de mantener a una población estable, capaz de asegurar la pervivencia de la devoción a sus santos tutelares. A este cuadro general habría que sumar los retos particulares planteados por las virtudes y limitaciones de las corporaciones eclesiásticas encargadas de administrar y promover el culto a los santos, a lo que se sumaba el caudal de anhelos, expectativas y necesidades específicas de los vecindarios que los acogían.

$\mathrm{Al}$ igual que en el resto de la América hispana, el conflicto entre las dos ramas del clero, el secular y el regular, se presentó una vez constituida la diócesis yucateca. Pero si los enfrentamientos entre el provincial franciscano, fray Diego de Landa, y el primer obispo, el también franciscano fray Francisco de Toral, pudieran definirse como un choque de voluntades mas no de proyectos, para los tiempos del tercer diocesano, fray Gregorio de Montalvo, ya era clara la línea que dividía los caminos de los dos cleros. ${ }^{12}$ La disputa por las doctrinas de indios enrareció la relación entre franciscanos y clérigos diocesanos, enzarzándose en una lucha que, con sus altiba-

11 López de Cogolludo, Diego: Historia de Yucatán, Madrid, 1688, Libro Cuarto, Cap. XV, pág. 221.

12 Sobre las relaciones entre franciscanos y clérigos diocesanos, véase los trabajos de Rocher Salas, Adriana: "Frailes y clérigos en Yucatán. Siglo XVII.", Hispania Sacra, vol. LV, n. ${ }^{\circ} 112$, Madrid, 2003, págs. 599-625; y "La política eclesiástica regia y sus efectos en la diócesis de Yucatán", Revista Complutense de Historia de América, vol. 30, Madrid, 2004, págs. 53-76. 
jos, mantuvo la estrategia de demeritar la obra del rival, con sus cultos y devociones incluidos. ${ }^{13}$

El culto a la Inmaculada Concepción constituye un caso paradigmático de la forma en que la rivalidad entre los dos cleros afectó la promoción de sus santos tutelares. Por sí mismo, el culto era controvertido. La idea de que María había sido concebida sin mácula no fue acogida de manera unánime en el seno de la propia Iglesia, que se vio dividida en dos bandos, maculistas e inmaculistas; y de entre estos últimos, sus figuras más destacadas se encontraban en las filas franciscanas. ${ }^{14}$ Fueron también portadores del cordón franciscano quienes llevaron la devoción al Nuevo Mundo. La cercanía del franciscanismo con el culto a la Inmaculada Concepción resultaría embarazosa para el clero secular campechano, participante activo en el conflicto de la diócesis yucateca contra la provincia de San Francisco por lo que, ante la disyuntiva de promover a su sagrada patrona, con la indirecta propaganda al franciscanismo que eso podía significar, o simplemente marginarla en beneficio de otros patronos más acordes con la clerecía local, optó por esta última opción. La portada de la Iglesia parroquial de la Inmaculada Concepción, concluida en 1760, refleja claramente esta estrategia. En ella se encuentran cinco nichos, uno de ellos en el centro, que contiene una imagen de la virgen María, que carece de los elementos iconográficos necesarios para identificarla como Inmaculada Concepción — las manos juntas, la luna, las estrellas o la serpiente bajo sus pies-; antes bien presenta las características de Nuestra Señora de la Asunción, pues tiene las manos separadas y el cuerpo en actitud de ascenso. Por encima de la escultura de la Virgen, en la parte más destacada del templo, se encuentra la Corona de San Pedro. Para subrayar el carácter de San Pedro como patrono, ya no de toda la Iglesia, por su

13 En 1712 el Procurador de la provincia franciscana de San José de Yucatán afirmó que el obispo fray Pedro Reyes se refería con desprecio a los franciscanos "y al propio san Francisco". AGI, 1.037, México, 14 de febrero de 1712. Años después, el Comisario de las provincias franciscanas de la Nueva España señaló al obispo Reyes por su empeño en "destruir a la religión de San Francisco y aun borrar la devoción al santísimo patriarca”. AGI, Indiferente, 3.054, Representación de fray Agustín de Mesones, Madrid, agosto 17 de 1721.

14 Baste recordar las figuras de la madre sor María de Águeda y de fray Juan Duns Scotto. Éste último fue autor de un argumento "probatorio" de que María fue concebida sin pecado original que, aún en nuestros días, es repetido en los tratados de Mariología y vidas de santos. El argumento de Scotto giró en torno a tres preguntas: ¿A Dios le convenía que su Madre naciera sin mancha del pecado original?, ¿Dios podía hacer que su madre naciera sin mancha del pecado original?, y finalmente, ¿lo que a Dios le conviene hacer lo hace? La respuesta afirmativa a esas preguntas constituiría la prueba "irrefutable" de la inmaculada concepción de la madre del salvador. Como ejemplo, véase P. Eliécer Sálesman: Vidas de santos. Octubre - Noviembre - Diciembre. 4. a ed., Editorial Centro don Bosco Apostolado Bíblico Católico, Bogotá, 2002, págs. 324. 325. 
condición de Sumo Pontífice, sino particular del clero diocesano, en la parte superior del acceso principal se labró una cruz de doble travesaño, símbolo de los arzobispos, patriarcas y fundadores de órdenes religiosas, en vez de la de triple travesaño, que es la que acompaña a los Papas. De esta manera, el frente de la principal iglesia del clero diocesano, la única con pretensiones estilísticas e iconográficas, en lugar de difundir la imagen y devoción hacia su patrona, hace promoción a la propia clerecía, con su empeño en mostrar a San Pedro como su padre, de la misma forma en que San Francisco lo era para los franciscanos o San Ignacio para los jesuitas. ${ }^{15}$

En Campeche, además de la parroquia de la Inmaculada Concepción, el clero diocesano tuvo bajo su cuidado las iglesias de Guadalupe, el Dulce Nombre de Jesús y San Román, mientras que los franciscanos se concentraron en la iglesia que presidía el barrio indígena de San Francisco. ${ }^{16}$ Sin embargo, pese a la amplitud del territorio bajo la administración del clero secular, serían los franciscanos el sector eclesiástico más activo y con mayor empatía con la población campechana. Mejor organizados, con mayores recursos humanos y materiales, los herederos de San Francisco tuvieron la capacidad de reaccionar de manera más eficiente a los requerimientos de la población local, los que estaban lejos de limitarse al ámbito espiritual. De esta manera, mientras la iglesia parroquial era demasiado pequeña y estaba en ruinas y la del Jesús carecía de ornamentos, vasos sagrados y demás instrumentos necesarios para celebrar dignamente el rito eucarístico y apenas había un ayudante de cura para cubrir las necesidades espirituales de los vecinos de los barrios de San Román y Guadalupe, por contraste, la casa franciscana tenía objetos de culto suficientes, solía albergar a por lo menos tres religiosos y poseía un convento sólido que, pese a sus problemas materiales, ${ }^{17}$ ofrecía refugio a los vecinos cuando los piratas se apoderaban de la villa. Por todo esto, no es de extrañar que cada domingo, los habitantes del

15 En los interminables litigios contra la provincia franciscana de Yucatán, los miembros del clero diocesano solían presentarse como "clérigos seculares de San Pedro de Yucatán”. Por ejemplo, véanse las representaciones incluidas en AGI, Escribanía, 308A, El Obispo, Deán y Cabildo de la Iglesia de Yucatán con la Religión de San Francisco sobre la administración de diferentes doctrinas, fecha inicial 1680, pendiente en 1702 .

16 Más adelante se fundó otro barrio de indígenas mayas yucatecos, puesto también bajo el cuidado de la provincia de San Francisco, que tuvo en Santa Lucía a su santa patrona. Sin embargo, al parecer, Santa Lucía Kinlakam fue considerado, hasta ya avanzado el siglo XVII, más que un barrio, un pueblo de indios.

17 Según fray Antonio de Ciudad Real, secretario de fray Alonso Ponce, Comisario General de las Provincias franciscanas de la Nueva España, el convento "estaba muy arruinado y se llovía". Ciudad Real, Antonio: Tratado curioso y docto de las grandezas de la Nueva España, UNAM, México, 1993, tomo II, pág. 355. 
centro de Campeche prefiriesen caminar "los dos tiros de mosquete" que separaban a San Francisco del centro, a apretujarse y llenarse los pies del lodo del cementerio parroquial, habida cuenta que no había espacio para todos en el interior de la iglesia de la Inmaculada Concepción; demasiadas incomodidades para la magra recompensa que les significaban las modestas y deslucidas ceremonias religiosas celebradas en la parroquia. ${ }^{18}$

A las carencias del clero diocesano habría que sumar otras más vinculadas con los perfiles de los santos patronos o de los barrios que los albergaron. La posible empatía entre la virgen de Guadalupe y los lugareños, producto de un origen geográfico común, pudo haberse erosionado debido al lento poblamiento del lugar, entorpecido por su ubicación en la zona limítrofe con el sistema de fortificaciones que protegía a Campeche de las acechanzas piráticas. ${ }^{19}$

En general, con excepción de San Francisco, ninguno de los primeros santos tutelares de San Francisco de Campeche tenía elementos que los acercasen a la población porteña. Ni tampoco alguno había "manifestado", mediante milagros u otros hechos sobrenaturales, su preferencia por la villa; lo más cercano a una señal divina se encuentra en la idea de la mano de la providencia interviniendo en las suertes que se echaron para seleccionar a San Román mártir.

San Francisco de Asís, en cambio, poseía mayores elementos para convertirse en el santo patrono de la emergente villa. Como patrono del puerto, de uno de sus barrios y de una de sus corporaciones eclesiásticas más importantes, tuvo a tres organizaciones para mantener y promover su culto: el cabildo de la villa, la cofradía de indios del barrio de San Francisco y la orden seráfica. Por si fuera poco, el pobre de Asís era considerado patrono de los comerciantes y mercaderes, perfil profesional desarrollado por un importante número de campechanos. ${ }^{20}$ Pero ni siquiera el culto al

18 AGI, Escribanía 305A, El Cabildo Justicia y Regimiento de la Villa de Campeche a Gonzalo de Salazar, obispo de Yucatán, sobre las obras de la Iglesia Mayor de dicha villa, Mérida de Yucatán, 1610.

19 Algunas de las limitaciones para poblar el barrio de Guadalupe pueden verse en "Reconocimiento y estado de la Provincia de Yucatán por el ingeniero Juan de Dios González, en Campeche a 18 de febrero de 1766", citado por Calderón Quijano, José Antonio: Fortificaciones en Nueva España. Gobierno del Estado de Veracruz, Escuela de Estudios Hispanoamericanos (CSIC), Madrid, 1984, págs. 402, 403. En general, el poblamiento de la villa de Campeche fue lento, como puede apreciarse en mapas de los siglos XVII y XVIII, que ponen de manifiesto que, incluso, la zona intramuros sólo estaba parcialmente poblada. Ibídem, figuras 128, 129 y 145.

20 Si bien el comercio podría considerarse lo opuesto a la pobreza evangélica pregonada por San Francisco, la actividad desarrollada por su padre, conocido comerciante de telas de Asís, ha servido para que la Iglesia añada a los comerciantes a la larga lista de beneficiarios del patronazgo del pobre de Asís. 
"místico ambulante" consiguió construir una leyenda basada en historias compartidas con el entorno local; al igual que sus homólogos, le hacían falta las reliquias, los milagros o alguna otra señal que hiciese sentir su presencia y que lograse darle carta de naturaleza ante el vecindario.

\section{En búsqueda de un protector celestial}

La búsqueda de santos propios, con una historia que transitase junto con la de Campeche, hizo que algunos barrios eligieran nuevos santos tutelares, con perfiles e historia más cercanos. El caso más exitoso lo constituyó el nuevo patrono del barrio de San Román, cuya historia cumplía con todos los requisitos para convertirlo en el patrono "universal" campechano. Según la tradición local, el Cristo de San Román había llegado a Campeche por elección propia, pues cuando una tormenta quiso impedir su arribo a tierras campechanas, el mismo crucificado, separado del madero que lo aprisionaba, tomó el timón y condujo su embarcación sana y salva hasta el puerto de Campeche. Era un cristo campechano y, por si fuera poco, su historia lo acercaba a todo ese amplio conglomerado de vecinos que tenían en el mar el principal centro de su actividad económica.

El barrio contaba con una población caracterizada por su heterogeneidad, pues a sus pobladores iniciales, los mexicas compañeros de Montejo en la conquista, se unieron criollos, mestizos y otras castas que tenían en común su dedicación a alguna actividad relacionada con el mar: marineros, carpinteros, calafateros de ribera y demás oficiales relacionados con la construcción naval, habida cuenta de que el astillero local se encontraba ubicado en los linderos del barrio. Es probable que la diversidad de orígenes sociales y raciales del vecindario sanromanero haya estado detrás del gran auge alcanzado por el culto al Cristo de San Román; necesitados de elementos que los hiciesen sentir parte de una misma comunidad, los habitantes del barrio encontraron en el Señor de San Román el símbolo que los identificaría como dignos hijos del barrio y del puerto.

A la historia de su origen, el Cristo de San Román sumó un considerable caudal de milagros vinculados con su potestad sobre los mares, virtudes taumatúrgicas y extraordinarias manifestaciones de su apego al barrio. ${ }^{21}$

21 Sobre el Cristo Negro, véanse las historias condensadas en la citada crónica de López de Cogolludo. 
Pero ni siquiera el cúmulo de milagros atribuidos a la imagen pudo convertirla en el patrono de todos los campechanos, pues, al parecer, su dominio sobre el mar se debilitaba cuando de los males terrestres se trataba. De esta manera, el Señor de San Román no fue invocado para proteger a Campeche de los piratas - ningún elemento del definitivo sistema de fortificaciones llevaría su nombre - ni contra los desastres naturales o las pestes. Probablemente no hubo quien tomara en sus manos la promoción de la devoción, pues el clero secular, escaso de prestigio y de personal, era incapaz de garantizar su culto permanente y la única cofradía asentada en la iglesia sanromanera prefirió promover la devoción a las ánimas del purgatorio por encima de la de su Cristo de ébano. Tampoco consiguió fidelidades sólidas fuera del barrio, como podía haber sido el caso de los navieros y armadores, quienes, una vez producido el arribo de la Compañía de Jesús a Campeche, abrazaron con entusiasmo el culto al "Príncipe del mar", San Francisco Javier. ${ }^{22}$

Para mediados del siglo XVII Campeche aún permanecía huérfana de ese sobrenatural protector que la guardase de los males de la tierra y del cielo. En 1648 toda la península yucateca se vio presa de una terrible epidemia. La ciudad de Mérida acudió rápidamente a implorar el auxilio de su protectora, la Virgen de Izamal, que recorrió en solemne procesión los kilómetros que separaban a su casa, en el pueblo de indios del mismo nombre, de la capital de la Gobernación. La llegada de la Virgen de Izamal consoló a los meridanos e incluso comenzaron las curaciones, las mismas que se atribuyeron al "beneficio de la impetración de la Reina de los Ángeles", razón por la cual el cabildo eclesiástico, en nombre de la ciudad y sus principales autoridades, decidió elegirla como su "patrona y abogada contra las pestes y enfermedades, así las que al presente hay en esta ciudad, como las que adelante hubiere". Pero en Campeche no tenemos registro de nada igual; al parecer, el puerto le rezó a todos sus santos y vírgenes por igual, en lugar de pedir la intercesión de sus dos principales patronos, San Francisco y el Cristo Negro, o del entonces beato Juan de Dios, fundador y patrono de los hermanos hospitalarios, administradores del único hospital de San Francisco de Campeche. ${ }^{23}$

22 Los hermanos de la Compañía de Jesús llegaron a Campeche en 1716. Archivo General de la Nación, (en adelante AGN), Jesuitas, I, 32, 9v. Yáñez, Francisco Javier: Relación Completa de las diligencias practicadas para conseguir y fundar esta Residencia de la Compañía que tiene por titulo de San José de Campeche, Campeche, 1752.

23 López de Cogolludo, Historia ... Libro Duodécimo, Cap. XIII. 
El arribo de la orden hospitalaria de San Juan de Dios entre 1626 y $1635^{24}$ no significó un impulso añadido a la devoción del nuevo beato. ${ }^{25} \mathrm{El}$ hospital, ubicado en uno de los extremos de la parte intramuros de la villa, carecía de vecindario propio; de hecho, habría que esperar hasta ya avanzado el siglo XIX para el poblamiento de la zona. Esta tardía urbanización podría ser una de las claves para comprender los muy limitados alcances de la devoción a San Juan de Dios, pues los vínculos creados a partir de la vecindad resultan fundamentales en la relación entre un santo patrono y una feligresía comprometida con el mantenimiento y difusión de su culto. Otra clave la proporciona el perfil mismo de la organización juanina. Su absorbente apostolado — el cuidado de los enfermos— la impulsó a construir una institución encerrada en sí misma, que sólo se abría cuando era absolutamente indispensable; prohibiciones como la de participar en procesiones y fiestas públicas, servir de albaceas o ser parte de procesos legales de terceros, tuvieron la finalidad de garantizar su exclusiva dedicación al trabajo hospitalario, aun a costa de reducir las posibles vías de comunicación con su entorno social. ${ }^{26}$ Sin embargo, si bien el culto a San Juan de Dios no pudo traspasar los límites inmediatos de su iglesia, sí que cumplió con la labor de convertirse en un detonante para la conformación de un sentimiento de identidad; los actuales vecinos de la iglesia se consideran parte de una pequeña comunidad, de un barrio, con "San Juanito" como principal signo identitario, aun cuando el resto de Campeche -incluida la cartografía oficialmira San Juan como un rincón más del centro histórico.

24 Existe cierta confusión respecto a la fecha exacta de llegada de los hospitalarios juaninos a Campeche. Diego López de Cogolludo y Manuel Lanz señalan 1626 como su año de entrada. Sin embargo, documentos de la Orden, el más antiguo de 1643, y del Cabildo de Campeche indican que tal hecho sucedió en 1635. Tal vez ocurriese que en 1626 hubo una avanzada que tuvo como misión realizar los trámites del traspaso del hospital, entonces administrado por el Cabildo local, pero no sería hasta 1635 cuando llegarían los enviados del Comisario de la Provincia del Espíritu Santo de San Juan de Dios para hacerse cargo de su administración. Véanse Biblioteca Nacional de España (en adelante BNE), M-3047, f. 159, Informe de la Fundación de la hospitalidad de San Juan de Dios del Espíritu Santo de Nueva España, 1643; AGN, Hospitales 34, 9, 458, Visita y cuentas del Convento hospital de la ciudad de Campeche, sin fecha; Santos, Juan: Cronología hospitalaria y resumen histórico del glorioso patriarca San Juan de Dios, Madrid, 1977, tomo II, pág. 569; Véase Lanz, Manuel: Historia del hospital de San Juan de Dios, en Pavón Abreu, Raúl. (comp.): Dos benefactores, dos Instituciones. Universidad Autónoma de Campeche, Campeche, 1991, pág. 75.

25 El portugués Juan Ciudad, mejor conocido como San Juan de Dios, fue beatificado el 21 de septiembre de 1630 por el papa Urbano VIII. El 15 de julio de 1691 fue canonizado por Inocencio XII.

26 Sobre las particularidades de la organización de los hospitalarios de San Juan de Dios y su actuación en Campeche, véase Rocher Salas, Adriana: Actividad de las órdenes religiosas en Campeche. Siglo XVIII. Tesis de doctorado inédita, Universidad Complutense de Madrid, Madrid, 2002, capítulo III. 
La orfandad espiritual de San Francisco de Campeche quedó de manifiesto en su encuentro con una providencial protectora. En 1649, "habiéndose padecido en esta tierra las calamidades y miserias que una peste ocasiona y para consuelo de otras ... tuvo por bien la majestad divina favorecer a sus fieles" permitiendo que un indígena encontrase un cuadro de la virgen del Rosario. Reportado el suceso a las autoridades civiles y eclesiásticas, la imagen fue llevada al convento franciscano en una procesión donde participaron españoles, mestizos, castas e indios, que iban "con luces de cera y mucha alegría de danzas a su modo". Pronto, desde la noche misma de su traslado, los milagros comenzaron a aparecer, prodigándose entre miembros de diferentes sectores del espectro social campechano, desde humildes indios hasta la esposa del alcalde ordinario. Por haber aparecido en la laguna de Hampolol, la imagen sería conocida como "Nuestra Señora de la Laguna", y la tierra y las raíces del árbol donde la encontraron fueron convertidas en reliquias. ${ }^{27}$

La historia de Nuestra Señora de la Laguna debe ser tomada con algunas precauciones, considerando los límites de nuestras fuentes, constreñidas al cronista franciscano Diego López de Cogolludo, quien tal vez hizo más grandes las maravillas de la imagen resguardada por sus hermanos de Campeche; al parecer, el cronista se hizo eco y le dio forma a la necesidad franciscana de contar con un patrono lo suficientemente popular como para hacer frente a las devociones de la clerecía diocesana, particularmente al culto del Cristo de San Román. Sin embargo, pese a estas consideraciones, la narración presenta algunos rasgos interesantes.

La aparición ocurrió en una coyuntura especialmente difícil, cuando la peste de 1648 había puesto de manifiesto las carencias de los santos patronos venerados por la población porteña. El hallazgo de la imagen se sitúa en una laguna y el descubrimiento lo hace un indígena, lo que nos indicaría un vínculo con la tradición prehispánica, plagada de seres sobrenaturales afincados en aguadas o lagunas. La simbiosis con la religiosidad cristiana aparece junto con la conversión en reliquias de los objetos cercanos a la imagen: la tierra, las raíces y las piedras del lugar de la aparición. La aspiración de tener una patrona que traspasase los límites de su barrio de acogida se refleja en el énfasis puesto en la heterogeneidad social y racial de la población devota y beneficiaria del culto. Sin embargo, tampoco Nuestra Señora de la Laguna pudo dejar una huella profunda en el

27 López de Cogolludo: Historia ... Libro Duodécimo, capítulos XIX y XX. 
vecindario, pues ya desde la época colonial se pierde el rastro del culto y de la fiesta —el 9 de mayo- en su honor.

El amanecer del siglo XVIII coincidió con la conclusión del recinto amurallado destinado a proteger la villa de Campeche del asedio de los filibusteros, que durante los dos siglos anteriores la habían hecho presa de su rapiña y sus desmanes. Sin embargo, para una sociedad que no construyó fronteras que separasen el cielo de la tierra, era imprescindible ostentar un sistema defensivo que combinase las armas terrenas con las espirituales, porque, como señalaba López de Cogolludo, "cuando el señor no guarda la ciudad, ¿qué importan diligencias humanas? ${ }^{28}$ Es por eso que la nomenclatura de la muralla y de los fuertes que componían el sistema defensivo constituye una buena guía de los santos patronos predilectos de la población porteña, de sus preocupaciones y de las corporaciones que impulsaron sus cultos. Ahí estuvieron presentes San Pedro, San José y San Francisco, patriarcas de clérigos diocesanos, franciscanos y del cabildo de la villa. También tuvo su lugar Santa Rosa de Lima, la terciaria dominica limeña que encarnó las reivindicaciones criollas de igualdad y grandeza frente a quienes consideraban a los nacidos en América españoles y cristianos de segunda. Por supuesto, no podía faltar un guerrero de las milicias celestiales contra los infieles, como era el caso del apóstol Santiago, que uniría su prodigiosa espada a las fuerzas de los ejércitos locales.

Pero el sistema de fortificaciones también tuvo ausencias notables, como las de San Juan de Dios, la Inmaculada Concepción y, principalmente, el Cristo de San Román. Antes de la conclusión del perímetro amurallado que envolvía el centro de la villa, el barrio de San Román dio su nombre a un fuerte y a una batería situados tierra adentro de su territorio, los mismos que fueron demolidos a finales del siglo XVII; casi un siglo después un proyecto para apuntalar las defensas campechanas consideró una batería para el barrio de San Román, pero fue desechado en beneficio de otro que incluyó fuertes y reductos dedicados a San José, San Miguel, San Matías, San Roberto y San Luis, mas a ninguno se le dio el patronazgo del señor de San Román. ${ }^{29}$

28 Ibídem, Libro Duodécimo, cap. XII, pág. 715.

29 Debemos hacer notar que a los antiguos fuertes del barrio sanromanero se les conocía indistintamente como San Román o Cristo Negro de San Román, clara muestra de, hasta dónde, el culto al Cristo de ébano había desplazado al del soldado romano martirizado en el siglo III. Sobre el sistema de fortificaciones de Campeche véase Calderón Quijano: Fortificaciones ... capítulos XII y XIII; Ortiz Lanz, José Enrique: Arquitectura militar de México, Secretaría de la Defensa Nacional, México, 1993, págs. 130-163. 


\section{Los obstáculos en la formación de una identidad común: la peculiaridad regional}

Las adaptaciones, los ensayos y las vueltas atrás en los esquemas implantados por los españoles en Campeche, entre los que se incluye la relación con sus santos patronos, estuvieron muy lejos de constituir fenómenos únicos; todo el Nuevo Mundo constituyó un laboratorio de experimentación, donde los conquistadores se vieron enfrentados a un mundo diferente del que conocían. No es de extrañar que las condiciones del proceso de conquista y posterior colonización de Yucatán obligaran a los hispanos a transitar por caminos nuevos, donde la experiencia vivida en el centro de México apenas era un difuso referente para la empresa de construir un régimen colonial en la península yucateca.

Poblada por mayas yucatecos, la península distaba de ser un centralizado y compacto imperio, similar al que conocieron los españoles en el centro de México. Dividida en cacicazgos independientes, Yucatán tuvo que ser conquistada palmo a palmo, pues la derrota de un cacique, la caída de una gran ciudad, no significaba más que la conquista de un territorio de límites imprecisos, considerando la compleja estructuración territorial de los cacicazgos yucatecos. ${ }^{30}$ Según Nancy Farriss, los indígenas yucatecos tenían "una larga historia de conquistas, gracias a la cual estaban psicológica y cognitivamente preparados para la llegada de los españoles", lo que permitió que la conquista hispana "fuese mucho menos catastrófica en lo inmediato para los mayas que para los mexicas". ${ }^{31}$ El sentido cíclico del tiempo, donde todas las cosas tienen un tiempo de vida previamente determinado, alimentó la idea de una posterior derrota española como consecuencia de un nuevo renacimiento maya.

A la ausencia de un sentido de derrota similar al que dominó en el mundo mexica, se añadió la permanencia de vastas zonas insumisas que tardarían décadas, incluso siglos, en rendirse ante el avance hispano, lo que les permitiría constituirse en auténticas válvulas de escape para los indígenas cansados de soportar las cargas impuestas por el esquema colonial. ${ }^{32}$ Por

30 Al respecto véase Quezada, Sergio: Pueblos y caciques yucateco, 1550-1580, El Colegio de México, México, 1993, capítulos I y II.

31 Farriss, Nancy: La sociedad maya bajo el dominio colonial, Alianza Editorial, Madrid, 1992, págs. 45 y 53.

32 Sobre estas regiones rebeldes véase el trabajo de Bracamonte Sosa, Pedro: La conquista inconclusa de Yucatán. Los mayas de la montaña, 1560-1680, CIESAS-Universidad de Quintana RooPorrúa, México, 2001. 
último, la aplastante mayoría numérica de la población maya yucateca con respecto a los españoles, negros, mestizos y demás castas constituyó el colofón de una tensa "pax colonial", caracterizada por la mutua desconfianza entre sus dos principales componentes: hispanos y mayas yucatecos..$^{33}$

La compleja relación entre conquistadores y conquistados impidió al criollismo incorporar el bagaje cultural prehispánico en el proceso de formación de una identidad propia, a la usanza de lo realizado en el centro del virreinato. ${ }^{34} \mathrm{Si}$ desde las primeras décadas de la segunda mitad del siglo XVI, en el centro de México la idolatría comenzó a verse como un fenómeno del pasado y la religión y los símbolos prehispánicos se consideraron neutralizados, "percibidos ya como inofensivos y por tanto y por fin como 'inocentes" ${ }^{35}$ en Yucatán, medio siglo después, la religión prehispánica aún se miraba como una ominosa sombra: “¿dónde se halla[n] ... tantos idólatras?, ¿igual irreverencia a los ministros de la iglesia?, ¿tan abundante balché libado a los ídolos? ¿dónde tantos ídolos venerados en los altares y llevados procesionalmente?" ${ }^{36}$ Un siglo más tarde, la rebelión de 1761 equiparó la rebeldía indígena con la religiosidad autóctona: "En muchos de los curatos de clérigos hallé idólatras, hechiceros y cómplices en esta última rebelión que tuvieron negando a Dios y a V. M. ... y no conocían por su Rey ni legislador más que al monstruoso idólatra Canek". ${ }^{37}$ En una época tan tardía como 1791 todavía había religiosos ensalzados en su combate a la idolatría: "y no pudiendo sufrir su virtud que en la provincia se conservase aún reliquias de la gentilidad, adorando a un ídolo con el nombre de Cayut o Dios de los Montes, ... lo destruyó y condujo al pueblo de Oxkutzcab la parte superior del cuerpo y en la plaza exhortó a los indios y en su presencia acabó de demolerlo, haciéndolos conocer el miserable error en que vivían de su poder" ${ }^{38}$ En este marco, no es de extrañar que para los hispanos de Yucatán la población indígena fuera, a la vez que su principal

33 Para una época tan tardía como 1789 el censo realizado por el Intendente don Lucas de Gálvez señalaba un total de 364.621 habitantes en la Gobernación, incluyendo los 30.000 de Tabasco, de los cuales el $73 \%$ eran indígenas; $15 \%$ blancos y mestizos y $12 \%$ negros y mulatos. Citado por Pérez Mallaina, Pablo: Comercio y Autonomía en la Intendencia de Yucatán, 1797-1814, Escuela de Estudios Hispanoamericanos (CSIC), Sevilla, 1978, págs. 13, 14, 22 y 26.

34 Véase el ya citado trabajo de Solange Alberro: El águila y la cruz...

35 Ibídem, pag. 73.

36 Sánchez de Aguilar, Pedro: "Informe contra los idólatras de Yucatán (1613)", en Anales del Museo Nacional de México, México, 1900, tomo VI, pág. 101.

37 AGI, México, 3.019. El obispo de Yucatán al rey, 8 de febrero de 1765.

38 AGN, Clero Regular y Secular, 142, 1,Testimonio de Pedro de Baranda, 11 de enero de 1791 . 
fuente de recursos, su mayor preocupación, debido a su supremacía numérica y a la pervivencia de una identidad propia, distinta de la española, con la religión y el idioma como sus más visibles signos identitarios. Por eso, consideramos que los recelos manifestados en 1663 por el obispo fray Luis de Cifuentes, respecto a que los indios eran muchos "y de poca confianza", son representativos del imaginario dominante respecto a los mayas yucatecos y su integración al mundo colonial.

En ese escenario dominado por el binomio dependencia-desconfianza marcando las relaciones entre españoles e indígenas, San Francisco de Campeche era, tal vez, la más hispana de las poblaciones urbanas yucatecas. Su porcentaje de españoles y criollos duplicaba al del resto de la gobernación, mientras los indígenas apenas fluctuaban entre el 4 y el $16 \%$ del total de sus habitantes. ${ }^{39} \mathrm{Su}$ menor proporción de población maya se tradujo en una también menor dependencia de la mano de obra y el tributo indígenas para el desarrollo de sus actividades económicas. ${ }^{40}$

Su condición de puerto de mar dotó a la villa de una personalidad diferenciada con respecto al resto de la península, marcada por el signo del comercio y la actividad marítima como sus principales distintivos. Es indudable que su condición portuaria influyó de manera determinante en esa constitución, como lo hizo también en la conformación de una población bastante heterogénea, donde la confluencia de numerosos conglomerados de negros y mulatos impidió que la relación blanco-indio se convirtiera en el eje de las relaciones económicas y sociales del lugar. Sin embargo, la desconfianza hacia la población indígena también se hizo presente, como lo puso de manifiesto la reacción producida ante el levantamiento indígena de 1761, liderado por Jacinto Canek. Aunque lejana a la revuelta, ocurrida en el pueblo de Cisteil, al oriente de Yucatán, la villa de Campeche se sintió igualmente amenazada: según el rector del colegio jesuita de San José estaban "por acá algo asustados con el alzamiento que intentaron los indios

39 En 1766 de los cerca de 18.000 habitantes de San Francisco de Campeche, únicamente 800 eran indios y el resto lo integraban 1.200 españoles peninsulares, 5.000 criollos, 8.000 mestizos y 3.000 negros y mulatos. Para 1810, entre sus 19.609 habitantes, sólo había 3.248 indios, mientras que cerca de 9.000 eran criollos y españoles. Rubio Mañé, José Ignacio: Noticias Históricas de Yucatán, Cuaderno 1, México, 1975, pág. 38; y Báez Landa, Mariano: Campeche la otra Puerta de México, Gobierno del Estado de Veracruz, Veracruz, 1991, Apéndice.

40 También ello explica por qué las encomiendas no alcanzaron en el distrito de Campeche un desarrollo similar al de Mérida y Valladolid. García Bernal, Manuela Cristina: Población y encomienda en Yucatán bajo los Austrias, Escuela de Estudios Hispanoamericanos, (CSIC), Sevilla, 1978, págs. $370-373$. 
[...] Era general la sublevación y, según lo habían dispuesto, la noche buena moriríamos todos sin remedio"; la ejecución de numerosos indígenas acusados de participar en el complot fue la lógica consecuencia del temor desatado. ${ }^{41}$

Además de mantener al indio en "policía y civilidad cristianas", San Francisco de Campeche también necesitaba controlar a su numerosa población flotante - viandantes, marineros y los soldados que la protegían del asedio pirata - e integrar como parte de su comunidad a los inmigrantes atraídos por la actividad del puerto. Y, al parecer, por lo menos en ciertos sectores, fracasó en el intento.

Algunos estudios sobre el cabildo local han señalado la gran movilidad de sus miembros, donde abundaron los inmigrantes y escasearon las dinastías familiares tan características de Mérida y de Valladolid, la otra villa urbana de la península. ${ }^{42}$ Aunque no se acierta a señalar si ésta falta de estabilidad se dio por la incapacidad de la propia élite para reproducirse o por su migración en busca de mejores horizontes — probablemente Mérida-, lo cierto es que Campeche careció de una élite fuerte, capaz de generar una idea, una imagen que pudiesen hacer suya todos los grupos y sectores que compartían el espacio común llamado San Francisco de Campeche.

La piratería, ese enemigo común que pudo ser el nudo que enlazara a toda la población, tuvo como principal consecuencia el amurallamiento del centro de la villa que marcó la definitiva división entre "los de afuera" y los de "adentro", los de oriente y occidente. La existencia de tres puertas de acceso — de Mar, San Román y Guadalupe-, a los que posteriormente se uniría una cuarta - la puerta de Tierra-, únicamente matizó el aislamiento de los barrios, por estar sujetas a un horario de apertura y cierre. ${ }^{43}$

Los periódicos cierres de las puertas de San Román y de Guadalupe, en un vano intento de frenar el contrabando, pusieron de manifiesto cómo la falta de comunicación entre los barrios también tenía consecuencias en el ámbito religioso. Cuando en 1736 el gobernador de Yucatán, Antonio de

41 AGN, Jesuitas, 1-12, 613, 3.651, Carta de Agustín Palomino a su provincial Pedro Reales, Campeche, 31 de diciembre de 1761.

42 Sobre los cabildos de las poblaciones urbanas de Yucatán durante el período colonial, véanse los trabajos de Martínez Ortega, Isabel: Estructura y Configuración socioeconómica de los cabildos de Yucatán. Siglo XVIII, Excma. Diputación Provincial de Sevilla, Sevilla, 1993; y González Muñoz, Victoria: Cabildos y grupos de poder en Yucatán (siglo XVIII), Exma. Diputación Provincial de Sevilla, Sevilla, 1994.

43 Calderón Quijano: Fortificaciones ... págs. 275-277. 
Benavides, solicitó la reapertura de las puertas laterales de la muralla, lo hizo considerando lo mucho que se había entibiado la devoción de los vecinos, quienes no podían acceder a los santuarios del Cristo de San Román y de Guadalupe ni siquiera en los días de fiesta. ${ }^{44}$

El fraccionamiento de la villa en barrios semiaislados debió constituir un formidable obstáculo para la expansión de los cultos a sus santos patronos que, más que unir, contribuyeron a la sectorización de San Francisco de Campeche pues, al tiempo que propiciaban y fortalecían identidades de barrio, fueron incapaces de traspasar fronteras y de arraigarse en nuevos territorios. Por lo menos hasta la conclusión del siglo XVII, es apreciable la fuerza del santo patrono en su propio barrio y su debilidad en los demás. Así, por ejemplo, entre los bautizados en la parroquia de la Inmaculada Concepción de 1635 a 1691, sólo hemos encontrado a dos a quienes se les impuso el nombre de Román: una niña, nativa del barrio del mismo nombre, y un niño, bautizado en fecha cercana a la fiesta del santo. ${ }^{45}$

\section{Consideraciones finales}

En la villa y puerto de San Francisco de Campeche todo pareció conjugarse para impedir la construcción de una identidad común a todos sus habitantes. Ante la imposibilidad de ensayar la creativa solución adoptada en el centro de México, donde se recuperaron y reutilizaron los símbolos religiosos prehispánicos en la construcción de una identidad criolla, al Campeche colonial sólo le quedaron opciones más tradicionales, como el culto a los santos patronos, para la creación de una conciencia identitaria local. Que esta salida todavía tenía vigencia entre los vecinos del puerto se aprecia en la creación de identidades de barrio a partir del culto a su santo patrono. Sin embargo, su territorio, dividido por las jurisdicciones civiles y eclesiásticas y por una omnipresente muralla, poco se prestaba para la implantación de un culto dominante, menos aún cuando se carecía de una elite con el suficiente prestigio para asegurar su difusión y permanencia.

Pero el último cuarto del siglo XVIII debió traer importantes cambios que en este trabajo nos ha sido imposible analizar: la pérdida de fuerza por

44 Ibídem.

45 Debemos anotar las carencias en la continuidad de los libros de bautismo, que tienen gruesos períodos vacíos, si bien de 1663 a 1691 prácticamente no hay interrupciones. Archivo Histórico de la Diócesis de Campeche, Parroquia del Sagrario, Libro de Bautismos, Caja 1 libros 1 y 2. 
parte del franciscanismo y la secularización de los curatos locales pudieron derribar algunas de las murallas que dividían al vecindario. Pero, sería tal vez la creciente rivalidad con Mérida la que volvería prioritaria la conformación de una imagen propia para los campechanos, ansiosos de legitimar su creciente anhelo de equipararse a la capital de la gobernación. Y en este proceso, la vuelta a los santos patronos como símbolos de una herencia y un proyecto común pudo ser nuevamente una opción viable; y si no, ¿quién mejor que el Cristo de San Román para encarnar la imagen de una ciudad que se veía a sí misma como porteña, cosmopolita y marinera, cuando frente a sus ojos su actividad portuaria se moría? La intervención de los cultos locales en la creación de un imaginario acorde con el Campeche separatista, independiente de Yucatán, constituye un hilo demasiado tentador para dejarlo suelto; no nos queda más que tirar de él como punto de partida para futuras investigaciones.

Recibido el 23 de diciembre de 2005

Aceptado el 7 de marzo de 2006 